\title{
Proteinuria in HIV Positive Children in Port Harcourt, Nigeria
}

\author{
Obiorah Christopher Chinedu ${ }^{1, *}$, and Daniel Chukwuemeka Obinabor ${ }^{2}$ \\ ${ }^{1}$ Department of Anatomical pathology, University of Port Harcourt Teaching Hospital, Port Harcourt, Nigeria \\ ${ }^{2}$ Department of Paediatrics, University of Port Harcourt Teaching Hospital, Port Harcourt, Nigeria
}

*Corresponding author: Obiorah Christopher Chinedu, Department of Anatomical pathology, University of Port Harcourt Teaching Hospital, Port Harcourt, Nigeria, Phone: +234-7030473512; E-mail: Christopher.obiorah@uniport.edu.ng

Received: 12 Feb, 2020 | Accepted: 26 Feb, 2020 | Published: 12 Mar, 2020

Citation: Obiorah CC, Daniel CO (2020) Proteinuria in HIV Positive Children in Port Harcourt, Nigeria. Int J Nephrol Kidney Fail 6(1): dx.doi. org/10.16966/2380-5498.191

Copyright: (C) 2020 Obiorah CC, et al. This is an open-access article distributed under the terms of the Creative Commons Attribution License, which permits unrestricted use, distribution, and reproduction in any medium, provided the original author and source are credited.

\section{Abstract}

Background: HIV-associated nephropathy (HIVAN) is a common complication of HIV infection and significant proteinuria is associated with HIVAN.

Aim: To determine the prevalence of proteinuria and the associated factors in HIV seropositive children seen at the University of Port Harcourt Teaching Hospital (UPTH).

Methodology: A prospective cross-sectional study of HIV positive patients seen by the infectious disease unit of the Paediatric department of UPTH between December 2017 and February 2018. Data on socio-demographic variables and clinical history were obtained from parents/guardians after informed consent was obtained. Patients were physically examined and dipstick analysis of midstream urine for proteinuria was done. Data were analyzed with SPSS version 20 .

Results: A total of 158 HIV seropositive patients aged two to fifteen years were studied. There were 78 (49.4\%) males and 80 (50.6\%) females. Mean and modal ages were $8.76 \pm 3.66$ and 8 years, respectively. Nine subjects ( 4 males; 5 females) had proteinuria, which translated to a proteinuria prevalence rate of $5.7 \%$. The gender difference was not statistically significant $(p$-value $=0.480)$. Although proteinuria occurred more in the subjects whose duration of HIV infection was 10 years and below, the relationship was not statistically significant. Eight (5.1\%) out of the 9 subjects with proteinuria had clinical stage 1 disease. However, there was no positive correlation between proteinuria and the clinical stage of HIV infection in the subjects.

Conclusion: The prevalence of proteinuria using dipstick urinalysis is low in HIV positive children seen in UPTH Port Harcourt.

Keywords: HIV; Children; Proteinuria; Port Harcourt; Prevalence

\section{Introduction}

Infection with Human Immunodeficiency Virus (HIV) is of public health concern worldwide but more in sub-Saharan Africa, home to $71 \%$ of the world's HIV infected people [1,2]. HIV which causes acquired immunodeficiency syndrome (AIDS) [1], is a major cause of infant and childhood morbidity and mortality in Africa and the rest of the world $[3,4]$. The virus causes progressive loss of the immune defense system leading to multiple infections with opportunistic agents and eventually death $[5,6]$. HIV was first reported in five homosexual men in Los Angeles [7] while in Nigeria, the first case was reported in a 13-year-old girl in 1986 [8].

Of the two types of HIV that infect humans-HIV-1 and HIV2, HIV-1 is more virulent, more easily transmissible and the cause of the vast majority of HIV infections globally [9]. HIV-2 is less transmissible and is largely confined to West Africa [9]. The virus affects virtually every system in the body including the kidneys with a resultant variety of renal abnormalities that culminate in HIVAN
[10,11]. Among children, most of the HIV-related renal diseases manifest as chronic kidney disease (CKD) [12].

The variety of acute and chronic syndromes that occur during the course of HIV infection can present with varied abnormal urinary findings including proteinuria, haematuria, glycosuria, urinary tract infections (UTI) and poor urinary concentrating ability [13]. Proteinuria with the subsequent development of nephrotic syndrome and CKD represents the commonest manifestations of HIV-related glomerular disease and is a sign of HIVAN [14-17].

Consequently, an avalanche of studies on proteinuria among HIV patients have been reported, some of which include: Han TM, et al. [18] in South Africa, who in a cross-sectional study observed that 6\% of HIV infected patients had varying degrees of proteinuria while in Tanzania, Fredrick F [19] reported microalbuminuria in $20.4 \%$ of $240 \mathrm{HIV}$-infected children. Also, in a multicenter cross-sectional study by Ekulu PM, et al. [20] in the Democratic Republic of Congo, the prevalence of proteinuria among 194 HIV-infected children 
was $23.8 \%$. HIV-infected children were noted to have seven times more probability of presenting with proteinuria than non-infected children. In Nigeria, while Ezeonwu BU, et al. [21] documented a 3.1\% prevalence of proteinuria among HIV-infected children in Enugu, South Eastern Nigeria, Mudi A, et al. [22] in Kano, North Central documented prevalence of $6.7 \%$. A previous study in our centre by Eke FU, et al. [23] showed a $12 \%$ prevalence of microalbuminuria in HIV positive children. Our study did not just determine the current prevalence of proteinuria in HIV seropositive children in Port Harcourt but assess factors associated with its manifestations. It also highlights the necessity for routine screening of children infected with the virus for renal diseases through urinalysis.

\section{Methodology}

This cross-sectional prospective study was carried out at the University of Port Harcourt Teaching Hospital (UPTH), Port Harcourt, Rivers State, Nigeria. UPTH, which has a bed capacity of 887 , is a major tertiary health institution in the State and a referral center for patients from neighboring states of Abia, Akwa Ibom, Bayelsa, and Imo. Port Harcourt, the state capital, is a cosmopolitan city with diverse Nigerian ethnic groups and foreigners. Rivers State covers a land area of 12,910 $\mathrm{km}$, has a population projected to be 5.2 million (as at last national cencus of 2006) [24] and is located in the south-south geopolitical zone of Nigeria. It is the hub of the Niger-Delta basin-an area known for environmental pollution caused by the poorly regulated activities of the oil and gas industry.

The subjects were HIV positive children consulted at the infectious disease unit of consultants' paediatrics clinic (CPC) between December 2017 and February 2018. Patients aged between two to fifteen years, whose parents/caregivers gave informed consent were enrolled in the study while similar patients younger than 2 years or older than 15 years as well as those whose parents/caregivers did not give informed consent were excluded. Printed informed consents were either signed or thumb printed by the parents/guardians of each child, after adequate explanation of the study protocols and usefulness. Questionnaires were also administered to the subjects through their parents/caregivers. The questionnaires which contain both closed and open-ended questions sought information on patient's biodata and brief medical history. Also, physical examination findings, as well as anthropometry and laboratory evaluation results were recorded. All recruited patients were assigned a study number that was entered into the administered questionnaire.

For each child, general examination for pallor, jaundice, peripheral edema, and peripheral lymphadenopathy was followed by a thorough systemic examination. Blood pressure was taken in the supine position using a certified Omron electronic sphygmomanometer in either of the upper limbs for each patient. Blood pressure above $120 \mathrm{~mm}$ $\mathrm{Hg}$ systolic and or diastolic above $80 \mathrm{~mm} \mathrm{Hg}$ was considered high. Standard weighing scale (model ZT-160, Good care, England) was used for weight measurement (in kilogram). Standard operating procedures were followed in each measurement. Height was measured using a stadiometer, following standard operating procedures. The length of patients who could not stand was measured using tape. The height or length and weight values obtained were used in calculating the body mass index (BMI), the latter being categorized into thin, normal, overweight and obese.

In collecting urine sample, strict aseptic measures were applied and universal precautions were observed. Pre labeled sterile urine bottles were used for collecting 4-5 $\mathrm{ml}$ of midstream urine samples while combi 10 dipsticks were used for urinalysis. For patients younger than five years of age, parents/care-givers were taught on the methodology of midstream urine collection and encouraged to do so. Proteinuria estimation was reported as: trace, $1+, 2+, 3+$ and $4+$, equivalent to 15 , $30,100,500$, and $1000 \mathrm{mg} / \mathrm{dl}$ of proteinuria, respectively.

The subjects' parents/guardians on a socioeconomic scale were classified into high, middle, and low classes using Oyedeji's classification scheme [25].

Data were entered into Microsoft Excel sheets and analyzed using the Statistical Package for Social Science Software (SPSS) version 20. Proportions or categorical parameters were analyzed with the chisquare $\left(\mathrm{X}^{2}\right)$ test. The confidence interval was set at $95 \%$ and a $\mathrm{p}$-value of $\leq 0.05$ was considered statistically significant.

Ethical clearance was obtained from the Research and Ethics committee of the University of Port Harcourt Teaching Hospital.

\section{Results}

Of the 158 HIV seropositive children who participated in the study, 78 were males $(49.4 \%)$ and 80 were females $(50.6 \%)$, giving a male to female ratio of $1: 1.03$. There was no gender predilection among the various age groups except in the 11-15 year age group where there were more females, though this was not statistically significant ( $p$-value $=0.790$ ). The difference in the sex distribution of the study population was not statistically significant $(\mathrm{p}=0.368)$. The mean age was $8.76 \pm 3.66$ years and the mode was 8 years. The majority of the subjects were above 5 years of age (Table 1).

The route of HIV infection was mother to child transmission in 155 (98.1\%) patients and blood transfusion in $3(1.9 \%)$ patients (Figure 1). The ages of subjects who got infected through blood transfusion, were four, five and eleven years. Of these three, the two older children (aged 5 and 11years) were infected at three months of age while the fouryear-old child was infected at three years of age.

Overall, children who had lived with the virus for 6-10 years were 63 cases (39.9\%) followed by those who had lived with the virus for upwards of ten years with 57 cases (36\%) while those who had the infection for a period between one and five years were 38 (24.1\%).

The majority of those on antiretroviral therapy i.e., highly active antiretroviral therapy (HAART), 78/158 (49.4\%) were those who had the virus for $1-5$ years, followed by $67(42.4 \%)$ children who were on HAART for 6-10 years. Only 13(8.2\%) patients were on antiretroviral medications for over ten years (Table 2).

The majority of the subjects, $134(84.8 \%)$ had clinical stage 1 disease. Only 5(3.2\%) had stage 2 disease and 19 (12\%) stage 4 none had stage 3 disease (Table 3 ).

The physical examination findings of the study population are shown in table 4 . The majority of the subjects-132 (83.5\%) had pallor of moderate to severe intensity while peripheral lymphadenopathy was found in $28(17.7 \%)$ subjects. The mean systolic and diastolic

Table 1: Distribution of age and sex of the study population.

\begin{tabular}{|l|c|c|c|}
\hline \multicolumn{4}{|c|}{ Subjects } \\
\hline \multicolumn{1}{|c|}{ Age (years) } & Male $\mathbf{n}(\%)$ & Female $\mathbf{n}(\%)$ & Total $\mathbf{n}(\%)$ \\
\hline$\leq 5$ & $21(26.9)$ & $17(21.3)$ & $38(24.1)$ \\
\hline $6-10$ & $32(41.0)$ & $31(38.7)$ & $63(39.9)$ \\
\hline $11-15$ & $25(32.1)$ & $32(40.0)$ & $57(36.0)$ \\
\hline Total & $\mathbf{7 8 ( 1 0 0 )}$ & $\mathbf{8 0 ( 1 0 0 )}$ & $\mathbf{1 5 8 ( 1 0 0 )}$ \\
\hline
\end{tabular}

Chi square $=1.271 ; p$-value $=0.530$ 
blood pressures of the subjects were $106.17 \pm 15.04 \mathrm{~mm} \mathrm{Hg}$ and 67.01 $\pm 11.27 \mathrm{~mm} \mathrm{Hg}$, respectively (Table 4). Although the mean BMI of the subjects was $0.41 \pm 1.73,19(12 \%)$ of the subjects recorded a BMI that classifies them as thin while 121(76.6\%) had a normal BMI (Figure 2).

As depicted in table 5, only nine (5.7\%) (4 males and 5 females) had proteinuria. Although there was proteinuria across all the age groups, predilection was for the 11-15 years age (Table 5). Proteinuria occurred more in the subjects whose duration of HIV infection was 10 years and below. Only one subject (1.8\%) with HIV infection lasting more than 10 years had proteinuria. However, the observed relationship was not statistically significant ( $\mathrm{p}$-value $=0.340$ ). This is shown in table 5 .

Out of 134 subjects with Clinical Stage one disease, 8(5.1\%) had proteinuria. Of the nine patients who had World Health Organization (WHO) stage II disease, one had proteinuria (Table 5).

One hundred and forty (88.6\%) of the subjects parents/guardians were of the high and middle socioeconomic classes (Figure 3).

\section{Discussion}

HIV-associated nephropathy is a common complication of HIV infection and significant proteinuria is associated with HIVAN. Urinalysis for proteinuria is a good and cheap way of assessing renal function.

Early detection of renal damage in the asymptomatic patient is important for early institutionalization of measures, which may reverse or slow down the progression of the underlying subclinical kidney disease to End-Stage Renal Disease (ESRD). This is a key preventive strategy against ESRD, especially as facilities for renal replacement therapy are presently limited, expensive and therefore largely inaccessible to the vast majority of the populous in Nigeria.

The $5.7 \%$ prevalence of proteinuria among HIV infected children obtained in this study is higher than the $3 \%$ reported by Steel-Duncan J, et al. [26] in a similar study that was carried out in Jamaica on 196 HIV-infected children. It is also higher than the $3.1 \%$ reported by Ezeonwu BU, et al. [21] in their study on $154 \mathrm{HIV}$ positive children in Enugu, South East Nigeria. On the contrary, our obtained 5.7\% prevalence rate of proteinuria is much lower than the findings of some other similar studies. For instance, Chaparro AI et al. [27] in their study in Miami Florida, USA reported 33\% while Ekulu PM, et al. [20] in



Table 2: Duration of HIV infection and highly active antiretroviral therapy (HAART) usage among subjects.

\begin{tabular}{|l|c|c|}
\hline \multicolumn{1}{|c|}{ Years } & Duration of Infection No (\%) & HAART Usage No (\%) \\
\hline 1-5years & $38(24.1)$ & $78(49.4)$ \\
\hline $6-10 y e a r s$ & $63(39.9)$ & $67(42.4)$ \\
\hline$>10 y e a r s$ & $57(36.0)$ & $13(8.2)$ \\
\hline Total & $158(100)$ & $158(100)$ \\
\hline
\end{tabular}

Table 3: Clinical staging of HIV infection among the subjects.

\begin{tabular}{|l|c|c|}
\hline \multicolumn{1}{|c|}{ Clinical stage } & Frequency $\mathbf{( n )}$ & Percentage (\%) \\
\hline Stage 1 & 134 & 84.8 \\
\hline Stage 2 & 5 & 3.2 \\
\hline Stage 3 & 0 & 0 \\
\hline Stage 4 & 19 & 12 \\
\hline Total & 158 & 100 \\
\hline
\end{tabular}

Table 4: Physical examination findings of the study population.

\begin{tabular}{|l|c|}
\hline \multicolumn{1}{|c|}{ Variables } & Subjects N=158 $\mathbf{n ~ ( \% ) ~}$ \\
\hline Present & $127(80.4)$ \\
\hline Absent & $31(19.6)$ \\
\hline \multicolumn{2}{|c|}{ Fever } \\
\hline Present & $3(1.9)$ \\
\hline Absent & $155(98.1)$ \\
\hline \multicolumn{2}{|c|}{ PLN } \\
\hline Present & $28(17.7)$ \\
\hline Absent & $130(82.3)$ \\
\hline \multicolumn{2}{|c|}{ Blood pressure } \\
\hline Elevated systolic BP only & $9(5.7)$ \\
\hline Elevated diastolic BP only & $4(2.5)$ \\
\hline Elevated systolic and diastolic BP & $11(7.0)$ \\
\hline Normal BP & $134(84.8)$ \\
\hline
\end{tabular}

PLN-Peripheral Lymphadenopathy

Table 5: Distribution of age of patients and proteinuria among subjects.

\begin{tabular}{|l|c|c|c|}
\hline \multicolumn{4}{|c|}{ Proteinuria } \\
\hline Age groups & Present $\mathbf{n}(\%)$ & Absent $\mathbf{n}(\%)$ & Total $\mathbf{n}(\%)$ \\
\hline 55 years & $2(5.3)$ & $36(94.7)$ & $149(94.3)$ \\
\hline $6-10$ years & $2(3.2)$ & $61(96.8)$ & $63(100.00)$ \\
\hline $11-15$ years & $5(8.8)$ & $52(91.2)$ & $57(100.0)$ \\
\hline Total & $\mathbf{9 ( 5 . 7 )}$ & $\mathbf{1 4 9}(\mathbf{9 4 . 3 )}$ & $\mathbf{1 5 8 ( 1 0 0 . 0 )}$ \\
\hline
\end{tabular}

Distribution of duration of HIV infection and proteinuria among subjects

\begin{tabular}{|l|c|c|c|}
\hline \multicolumn{4}{|c|}{ Duration of HIV infection } \\
\hline 1-5years & $4(10.5)$ & $34(89.5)$ & $38(100.0)$ \\
\hline $6-10 y e a r s$ & $4(6.3)$ & $59(93.7)$ & $63(100.0)$ \\
\hline$>10 y e a r s$ & $1(1.8)$ & $56(98.2)$ & $57(100.0)$ \\
\hline Total & $\mathbf{9 ( 5 . 7 )}$ & $\mathbf{1 4 9}(\mathbf{9 4 . 3 )}$ & $\mathbf{1 5 8 ( 1 0 0 . 0 )}$ \\
\hline
\end{tabular}

Distribution of WHO clinical stages and proteinuria among subjects Clinical staging

\begin{tabular}{|l|c|c|c|}
\multicolumn{5}{|c|}{ Clinical staging } \\
\hline Stage I & $8(5.1)$ & $141(94.6)$ & $149(100.0)$ \\
\hline Stage II & $1(0.6)$ & $8(88.9)$ & $9(100.0)$ \\
\hline Total & $\mathbf{9 ( 5 . 7 )}$ & $\mathbf{1 4 9 ( 9 4 . 3 )}$ & $\mathbf{1 5 8 ( 1 0 0 . 0 )}$ \\
\hline
\end{tabular}



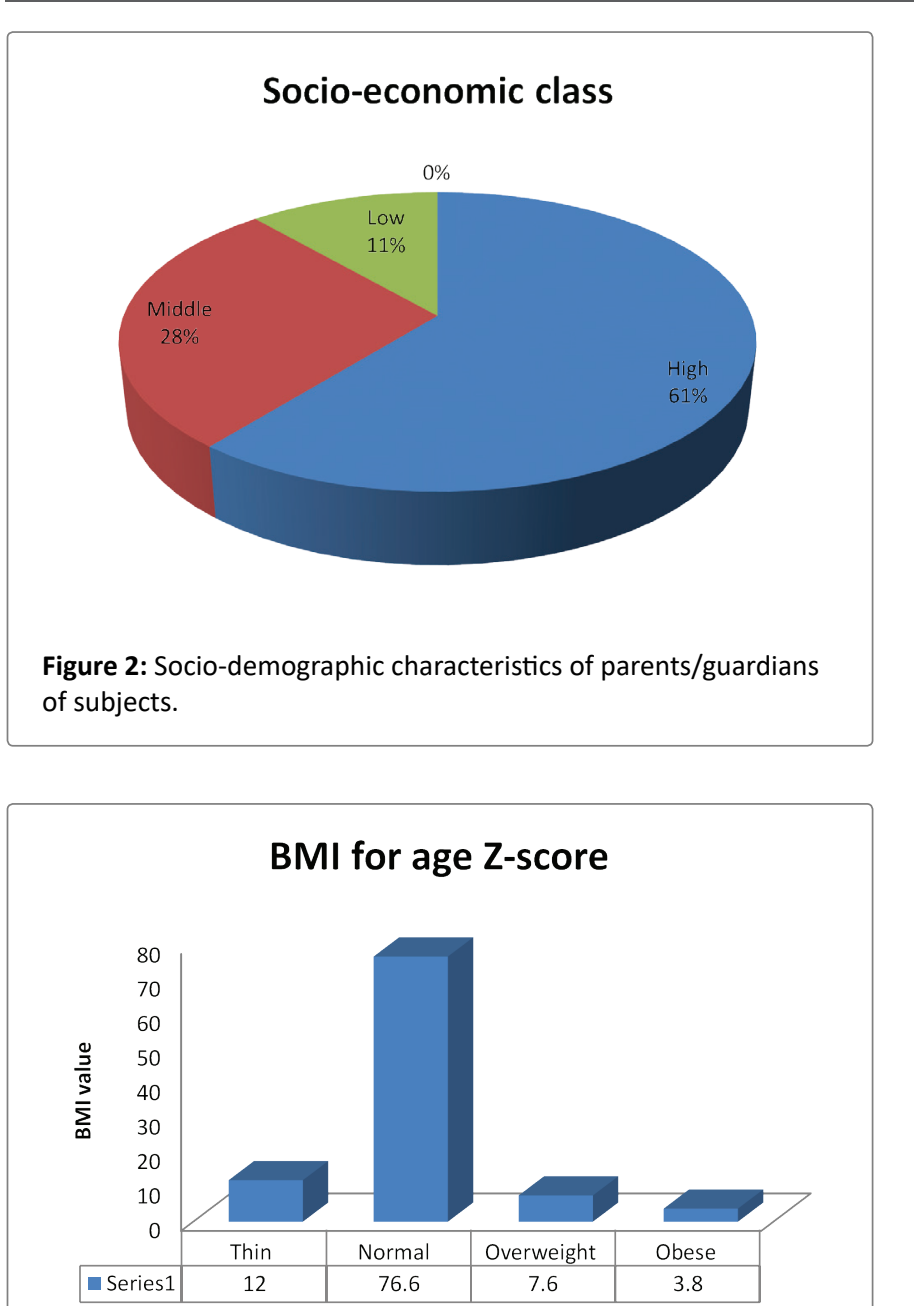

Figure 3: Distribution of BMI of the study population

Kinshasa, Congo reported 23.8\% and Esezobor CI, et al. [28] in Lagos, South South Nigeria reported 20.5\%. Also, in Mumbai, India, Shah I, et al. [29] reported a prevalence rate of $10.7 \%$. The varying prevalence of proteinuria among HIV-infected children as documented above may be due to the differences in the study protocols. For instance, the findings of the study by Shah I, et al. [29] and Ekulu PM, et al. [20] are higher than ours probably because the children in Shah I, et al. study [29] were not on antiretroviral therapy while the subjects in our study were on HAART. It is possible that those patients studied by Chaparro AI, et al. [27] were also not on HAART since HAART was introduced in 1996, eight years after the study was conducted-1988. Besides, in this study, proteinuria was only determined by dipstick which does not give as much good yield and quantification as spot urine proteincreatinine ratio.

There was no positive correlation between proteinuria and the duration of HIV infection in the subjects because the number of patients with proteinuria was not much-only 9. Among the nine subjects that had proteinuria, only one had the viral infection for over ten years. This low rate of proteinuria may be due to good compliance with HAART and routine follow up visits.

However, what is clear is that proteinuria is a warning sign for HIVAN [15-17]. HIVAN usually occurs in advanced disease and approximately $80 \%$ of patients with HIVAN have a CD4 count of less than 200 [17]. HIVAN presents with nephrotic syndrome and progressive kidney failure. Some published reports described heavy proteinuria in children with HIV infection [17,30]. None of the subjects in this study had heavy proteinuria. The subjects had one or two plus protein, equivalent to $30 \mathrm{mg}$ and $100 \mathrm{mg}$, respectively. This study differs from the Jamaican study by Steel-Duncan J, et al. [26] in which they found that all the children had advanced stages of HIV disease and nephrotic range proteinuria. Although we did not assess the CD4 counts of the subjects as it was not on the original work scope, none of the subjects had HIVAN given the fact that there was none with heavy proteinuria or clinical features of advanced HIV disease.

The route of transmission of HIV infection for 155 (98.1\%) was vertical transmission (mother to child) while for 3 (1.9\%) subjects, it was blood transfusion. This compares well with the findings of Countsoudis A, et al, [31] who documented that vertical transmission accounted for about $90 \%$ of cases of HIV infection in children. There is a need for increased advocacy by obstetricians and other health workers for the adoption and compliance with preventive measures against vertical transmission.

The prevalence of peripheral lymphadenopathy for the subjects was $18.35 \%$. This is low when compared to $57.75 \%$ reported by Pol RR, et al. [32] in Karnataka, India. This difference may be due to the smaller sample size in Pol RR, et al. [32] work compared with ours. It is also possible that the different findings represent environmental influences on the same disease entity and variation in manifestation patterns. Enlarged lymph nodes are a frequent finding in HIV-infected patients and are known as Persistent Generalized Lymphadenopathy (PGL) [33]. Since lymphocytes are the target cells for HIV infection, lymphadenopathy is one of the most common and consistent symptoms of the infection. Lymphadenopathy can be found in every stage of HIV infection. Nevertheless, it is not a specific sign for HIV infection as it can also be found in HIV negative individuals as a result of various infectious diseases [33]. However, there is paucity of research works on the prevalence of lymphadenopathy in paediatric HIV infection.

The prevalence of elevated blood pressure in the subjects was $15.2 \%$. This is comparable to $19.6 \%$ reported by Chatterton-Kirchmeir S, et al. [34] in Madrid. Our finding was based on a single blood pressure measurement recorded in medical charts adjusted for sex, age and height. Chatterton-Kirchmeir S, et al. [34] found that cardiovascular disease in HIV-infected patients might be related to accelerated atherosclerosis with intimal and medial thickening, which is ascribed to direct viral effects, associated chronic inflammation, T-cell and monocyte activation and antiretroviral treatment-associated metabolic alterations. Elevated blood pressure was used in this study instead of hypertension since not up to three measurements of blood pressure were done for the study population. However, 134 (84.8\%) subjects in this study had normal blood pressure. This may further assert that the virus has not adversely affected their kidneys.

The prevalence of wasting among the subjects was $12 \%$. This value is lower than $52 \%$ reported by Cames C, et al. [35] who studied growth retardation in HIV-infected Senegalese children aged 2-16 years. In Europe, the prevalence of wasting for $184 \mathrm{HIV}$-infected children studied by Newell ML, et al. [36] was $44 \%$. Newell concluded that HIVinfected children were significantly lighter in weight than uninfected children. The enormous disparity in the prevalence of wasting obtained in this study as compared to the values obtained by Cames C, et al. [35] and Newell ML, et al. [36] is a clear indication that most of the subjects in this study were compliant with their anti-retroviral therapy and follow up visits. It also further suggests that the parents and caregivers of the subjects were in good socioeconomic placement, which enabled 
the procurement and provision of adequate nutrition for the subjects. Accordingly, about $61 \%$ of the parents and caregivers belong to the high socioeconomic category hence may have ensured and enforced proper compliance with medications and regular follow up visits.

This work was limited by the difficulty in convincing parents and caregivers to give consent to the study. Also, proteinuria would have been more objectively quantified with urine protein-creatinine ratio. However, this investigation was not obtainable in the hospital laboratory at the time of this study. Limitations of finance precluded other supportive investigations of the patients like CD4 count.

\section{Conclusion}

The prevalence of proteinuria among HIV infected children in UPTH is low. This may suggest good control of viremia among the subjects who are on HAART. Routine screening of such children through urinalysis is also highlighted.

\section{Conflict of Interest}

None is declared.

\section{Acknowledgment}

We are grateful to the children who participated in this study and their parents and caregivers for the consents they gave, without which this study would not have been possible. We are also grateful to the resident doctors who served as research assistants in this work for their dedication. Finally, we are appreciative of Professors Ifeoma Anochie and Nwadiuto Akani for finding time to read through the work and give their most valuable criticisms.

\section{References}

1. De Cock KM, Jaffe HW, Curran JW (2012) The evolving epidemiology of HIV/AIDS. AIDS 26: 1205-1213.

2. Biswas MHA (2012) AIDS epidemic worldwide and the millennium development strategies: A light for lives. HIV \& AIDS Review 11: 87-94.

3. UNICEF, WHO, UNAIDS (2008) Children and AIDS: Country Fact Sheets.

4. Tindyebwa D, Kayita J, Musoke P, Eley B, Nduati R, et al. (2006) Handbook on paediatric AIDS in Africa. by the African Network for the Care of Children Affected by AIDS. USAID.

5. Williams D, Lewis M (2011) Pathogenesis and treatment of oral candidosis. J Oral Microbiol 3: 5771.

6. Masekela R, Anderson R, Moodley T, Kitchin OP, Risenga SM, et al. (2012) HIV-related bronchiectasis in children: an emerging spectre in high tuberculosis burden areas. Int J Tuberc Lung Dis 16: 114-119.

7. Centers for Disease Control (CDC) (1981) Pneumocystis pneumonia--Los Angeles. Morbidity and Mortality Weekly Report 30: 1-3.

8. Joint United Nations Programme on HIV/AIDS (UNAIDS) (2004) Report on the global AIDS epidemic. $4^{\text {th }}$ global report, UNAIDS, Geneva, Switzerland.

9. Reeves JD, Doms RW (2002) Human immunodeficiency virus type 2 . J Gen Virol 83: 1253-1265.

10. Bruggeman LA, Ross MD, Tanji N, Cara A, Dikman S, et al. (2000) Renal epithelium is a previously unrecognized site of HIV-1 infection. J Am Soc Nephrol 11: 2079-2087.

11. Gottlieb MS, Schroff R, Schanker HM, Weisman JD, Fan PT, et al. (1981) Pneumocystis carinii pneumonia and mucosal candidiasis in previously healthy homosexual men: evidence of a new acquired cellular immunodeficiency. N Engl J Med 305: 1425-1431.
12. Connor E, Gupta S, Joshi V, DiCarlo F, Offenberger J, et al. (1988) Acquired immunodeficiency syndrome-associated renal disease in children. J Pediatr 113: 39-44.

13. Ezeonwu BU, Oguonu T, Ikefuna AN, Okafor HU (2013) Urinary findings in HIV positive children by dipstick screening test in Enugu. Niger J Paed 40: 65-69.

14. Ramsuran D, Bhimma R, Ramdial PK, Naicker E, Adhikari M, et al. (2012) The spectrum of HIV-related nephropathy in children. Pediatr Nephrol 27: 821-827.

15. Abitbol CL, Strauss J, Zilleruelo G, Montané B, Rodriguez E (1996) Validity of random urines to quantitate proteinuria in children with human immunodeficiency virus nephropathy. Pediatr Nephrol 10: 598-601.

16. Dondo V, Mujuru HA, Nathoo KJ, Chirehwa M, Mufandaedza Z (2013) Renal abnormalities among HIV-infected, antiretroviral naive children, Harare, Zimbabwe: a cross-sectional study. BMC Pediatr 13: 75

17. Ray PE, Rakusan T, Loechelt BJ, Selby DM, Liu XH, et al. (1998) Human immunodeficiency virus (HIV)-associated nephropathy in children from the Washington, D.C area: 12 years' experience. Semin Nephrol 18: 396-405.

18. Han TM, Naicker S, Ramdial PK, Assounga AG (2006) A crosssectional study of HIV-seropositive patients with varying degrees of proteinuria in South Africa. Kidney Int 69: 2243-2250.

19. Fredrick $F(2012)$ Microalbuminuria, proteinuria and associated factors among HIV infected children attending HIV care and treatment clinic at Muhimbili national hospital, Dar es salaam, Tanzania. Muhimbili University of Health and Allied Sciences.

20. Ekulu PM, Nseka NM, Aloni MN, Gini JL, Makulo JR, et al. (2012) Prevalence of proteinuria and its association with HIV/AIDS in Congolese children living in Kinshasa, Democratic Republic of Congo. Nephrol Ther 8: 163-167.

21. Ezeonwu BU, Okafor HU, Ikefuna AN, Oguonu T (2012) Screening for Microalbuminuria in HIV-Positive Children in Enugu. Int J Nephrol 2012: 805834.

22. Mudi A, Alhaj BU, Hassan-Hanga F, Yahaya IA (2014) Persistent microalbuminuria in human immunodeficiency virus infected children in Kano, Nigeria. Int J Nephrol 2014: 567838.

23. Eke FU, Anochie IC, Okpere AN, Eneh AU, Ugwu RN, et al. (2010) Microalbuminuria in children with human immunodeficiency virus (HIV) infection in Port Harcourt, Nigeria. Niger J Med 19: 298-301.

24. National Population Commission (2010) Federal Republic of Nigeria. 2006 Population and Housing Census. Population Distribution by Age \& Sex. Priority Table Volume IV.

25. Oyedeji GA (1985) Socio-economic and cultural background of hospitalized children in llesa. Niger J Paediatr 12: 111-117.

26. Steel-Duncan J, Miller M, Pierre RB, Dunkley-Thompson J, Palmer P, et al. (2008) Renal manifestations in HIV-infected Jamaican children. West Indian Med J 57: 246-252.

27. Chaparro Al, Mitchell CD, Abitbol CL, Wilkinson JD, Baldarrago $\mathrm{G}$, et al. (2008) Proteinuria in children infected with the human immunodeficiency virus. J Pediatr 152: 844-849.

28. Esezobor Cl, Iroha E, Onifade E, Akinsulie AO, Temiye EO, et al. (2010) Prevalence of proteinuria among HIV-infected children attending a tertiary hospital in Lagos, Nigeria. J Trop Pediatr 56: 187-190.

29. Shah I, Gupta S, Shah DM, Dhabe H, Lala M (2012) Renal manifestations of HIV infected highly active antiretroviral therapy naive children in India. World J Pediatr 8: 252-255. 
30. Anochie IC, Eke FU, Okpere AN (2008) Human immunodeficiency virus-associated nephropathy (HIVAN) in Nigerian children. Pediatr Nephrol 23: 117-122.

31. Coutsoudis A, Kwaan L, Thomson M (2010) Prevention of vertical transmission of HIV-1 in resource-limited settings. Expert Rev Anti Infect Ther 8: 1163-1175.

32. Pol RR, Shepur TA, Ratageri VH (2007) Clinico-laboratory profile of pediatric HIV in Karnataka. The Indian J Pediatr 74: 1071-1075.

33. Chang KL, Arber DA, Weiss LM (2009) Lymphadenopathy: HIVrelated lymphadenopathy. In: Weidner N, Cote RJ, Suster S, Weiss LM (eds) Modern Surgical Pathology. Elsevier Health Sciences 14311451.
34. Chatterton-Kirchmeier S, Camacho-Gonzalez AF, McCracken CE, Chakraborty R, Batisky DL (2015) Increased prevalence of elevated blood pressures in HIV-infected children, adolescents and young adults. Pediatr Infect Dis J 34: 610-614.

35. Cames C, Pascal L, Diack A, Mbodj H, Ouattara B, et al. (2017) Risk Factors for Growth Retardation in HIV-infected Senegalese Children on Antiretroviral Treatment: The ANRS 12279 MAGGSEN Pediatric Cohort Study. Pediatr Infect Dis J 36: e87-e92.

36. Newell ML, Bovia MC, Peckham C, European Collaborative Study (2003) Height, weight and growth in children born to mothers with HIV-1 infection in Europe. Pediatrics 111: e52-e60. 